Passagens. Revista Internacional de História Política e Cultura Jurídica

Rio de Janeiro: vol. 7, no.1, janeiro-abril, 2015, p. 94-108.

DOI: 10.5533/1984-2503-20157105

\title{
A importância de olhar para trás: 0 recurso de apreensão de livro e os tempos em que vivemos
}

\author{
Leandro Moreira Valente Barbas ${ }^{1}$
}

\begin{abstract}
"A história do Direito e da Justiça são pouco conhecidas no Brasil. Pouco se sabe da atividade dos juízes, advogados, promotores públicos e muito menos dos servidores do Judiciário. No entanto, muito há de interessante a comentar. $E$ mais ainda a evitar, pois conhecer o passado significa errar menos no futuro." ${ }^{2}$
\end{abstract}

\section{Resumo}

Já houve, no âmbito do Supremo Tribunal Federal, categoria processual intitulada "recurso de apreensão de livro". Baseando-se em caso verídico resgatado da base de dados daquela Corte, fazemos breve análise do antigo julgado ali proferido. Emblemático, trata do litígio envolvendo a apreensão, no Estado de São Paulo, de exemplares da obra "O Bom Crioulo", de Adolfo Caminha. Tal caso é trazido à tona pelo seu amplo potencial de expor a moldura jurídica dada a determinados princípios na época, comparando-os brevemente com a forma pela qual são hoje compreendidos. Através desta exposição, passamos a refletir sobre os paradigmas de nosso passado jurídico para daí extrair valorosas lições à conduta que hoje devem adotar os juristas.

Palavras-chave: recurso de apreensão de livro; jurisprudência; Supremo Tribunal Federal.

\footnotetext{
${ }_{1}^{1}$ Advogado graduado pela Escola de Direito de São Paulo da Fundação Getúlio Vargas - FGV-SP/EDESP. Mestrando em Direito Político e Econômico na Universidade Presbiteriana Mackenzie-SP. Advogado de Advocacia Masato Ninomiya (SP). E-mail: leandro.barbas@gmail.com

${ }^{2}$ Freitas, Vladmir Passos de (2009). Pouco se sabe sobre o Tribunal de Segurança Nacional. In Revista Consultor Jurídico, São Paulo. Disponível em: <http://www.conjur.com.br/2009-mai-31/brasil-sabe-tribunalseguranca-nacional>. Acesso em: 12 mai. 2014.
} 
De la importancia de mirar para atrás: El recurso de incautación de libro y los tiempos en que vivimos

\section{Resumen}

En el ámbito del Supremo Tribunal Federal, se encontraba una categoría procesal intitulada "recurso de incautación de libro". Basándose en un caso verídico rescatado de la base de datos de aquella Corte, se realiza un breve análisis de este juicio antiguo entonces proferido. Caso emblemático, trata del litigio vinculado a la incautación, en el Estado de San Pablo, de ejemplares de la obra "O Bom Crioulo" (El Buen Criollo), de Adolfo Caminha. Se lleva a la luz este caso por el amplio potencial que tiene de exponer la moldura jurídica que determinaba algunos principios en esta época, comparándolos brevemente con la forma en que los comprendemos hoy. A través de esta exposición, se propone una reflexión sobre los paradigmas de nuestro pasado jurídico que permite sacar valiosas lecciones para guiar a los juristas en la actitud que deben tener hoy en día.

Palabras clave: Recurso de incautación de libro; jurisprudencia; Supremo Tribunal Federal.

The importance of looking back: The document search and seizure order and the times we live in

\section{Abstract}

The Supreme Federal Court once featured a category of procedure known as a "document search and seizure order". Based on a real-life case retrieved from the court's own database, we conduct a brief analysis of the judgment made. An emblematic case, it deals with a dispute involving the seizure of copies of the work entitled "O Bom Crioulo" [The Good Creole] by Adolfo Caminha in São Paulo. We have selected it due to its ample potential to demonstrate the legal framework impressed upon certain principles prevailing at the time, briefly comparing them with the way in which they are understood today. This analysis then leads us to reflect on the paradigms of our juridical past in order to extract valuable lessons on the behavior that jurists should adopt nowadays.

Keywords: Document search and seizure order; jurisprudence; Supreme Federal Court.

\section{L'importance du regard en arrière : la mise sous séquestre des livres et les temps où nous vivons \\ Résumé}

Dans le cadre de la Cour suprême fédérale a existé une catégorie de procédure intitulée "mise sous séquestre de livre ". Sur la base d'un cas réel issu de la base de données de cette cour, nous avons procédé à une brève analyse de la sentence proférée à cette occasion. II s'agit d'un litige emblématique impliquant la saisie, dans l'État de São Paulo, d'exemplaires de l'ouvrage O Bom Crioulo, d'Adolfo Caminha. Nous avons choisi d'exposer ce cas en raison de son potentiel à nous montrer le cadre juridique donné à certains principes de l'époque, que l'on comparera brièvement à la forme selon laquelle on les comprend aujourd'hui. Cette analyse nous permettra de réfléchir aux paradigmes de notre passé juridique afin d'en extraire de précieuses leçons pour la conduite que doivent aujourd'hui adopter les juristes.

Mots-clés : Mise sous séquestre de livre ; jurisprudence ; Cour suprême fédérale.

\section{往回头看的重要性：没收书籍和我们所生活的年代}

摘要:

巴西联邦最高法院，在程续范畴里，有一个叫 “请求没收书籍”

的程序。基于该法院的发生过的真实事件, 我们分析一个有代表性的旧案例判决。这个案例发生在圣保罗州, 法院判决没收书籍 “土生杂种” (“O Bom Crioulo”)，作者是 Adolfo Caminha. 分析这个案例的目的是因为此项判决最能体现那个时代的法官的判案框架和原则, 这些原则和目前我们的时代 截然不同。通过分析, 我们可以对我们过去的司法标准和范畴进行反思, 从中吸取有益的关于法官道德行为的 教训。

关键词: 请求没收书籍, 法规法律, 最高联邦法院。 


\section{Introdução}

Não é novidade, eis que tais fatos nos são narrados desde os primórdios de qualquer educação elementar, que o Brasil viveu sob regimes ditatoriais durante a maior parte do século passado.

O calor das discussões, principalmente na área jurídica, costuma estar no período entre 1964 e 1988, e tal fato é até natural. Nossa atual Constituição Federal é reação direta àqueles tempos. Foi elaborada com base na experiência ali imediatamente vivida. Logo, uma ampla maioria dos tópicos hoje discutidos em Direito fará provável contraponto ao status quo daquela época, e não de outras. Afinal, não se deseja o retorno daquele ambiente.

Por este motivo é que escrever qualquer coisa sobre o período dos anos 30 , também turbulentos, é um desafio. Significa olhar através da sombra deixada pelos tempos vividos pelos nossos pais, para enxergar a turbulência em meio a qual viveram nossos avós.

O desafio se mostra ainda mais especial quando levamos em conta a geração que representamos: a de nascidos em 1988. Justamente aquela que, dentre os profissionais hoje recém-chegados à advocacia e ao Direito, desde o princípio da vida vivenciou - e tal é motivo de orgulho - tempos de democracia.

\section{Nossa inspiração para a escrita: um documento coberto de pó}

Em se tratando da introdução a nosso breve escrito, nada mais necessário que explicarmos sobre o que escreveremos. O tema de nosso artigo é uma espécie processual já há muito tempo extinta.

Num certo dia, sem motivo, e de certo modo por equívoco, viemos a nos deparar com documento antigo acessível pelo site do Supremo Tribunal Federal (STF). Justamente a decisão que nos serve de inspiração para a escrita.

Não é de amplo conhecimento dos juristas a existência do que o STF nomeou COLAC - Coletânea de Acórdãos. Trata-se, basicamente, de um resgate de decisões 
antigas - muitas delas históricas - proferidas por aquela Corte. Eis que ao digitarmos por engano, o número "1" no campo de pesquisa por acórdãos em inteiro teor ${ }^{3}$, deparamonos com figura peculiar: a existência de uma decisão oriunda de gênero processual chamado "Recurso de Apreensão de Livro" (RAL), gravado - justamente - com o número 1.

O site, felizmente, permite acesso à íntegra do documento. Trata-se de processo julgado pelo Supremo Tribunal em 1938, cuja questão jurídica faz referência à competência do então existente Tribunal de Segurança Nacional $(\mathrm{TSN})^{4}$ para apreciar recursos contra ato de juiz que considerasse ilegais as decisões governamentais de se apreender obras, no caso, literárias.

O conteúdo do acórdão, por hoje obviamente distante da realidade jurídica, em situações de normalidade seria prontamente ignorado, considerado "coisa do passado" ou "apenas um documento cheio de pó". Nós, entretanto, sempre convivemos com a inquietação e a curiosidade de saber mais sobre aquele tipo de discussão, à época uma modalidade processual codificada ${ }^{5}$ no âmbito do STF.

Estivemos sempre a guardar tal inquietação, que em tempo nos permitimos explorar, dentro do contexto proporcionado pela produção deste escrito.

\section{Brevemente: 0 Recurso de apreensão de livro $n^{\circ} .1$}

Trata-se de caso de relatoria do Ministro EDUARDO ESPINOLA, julgado em 10/06/1938. Relata-se, no teor, que 772 exemplares da obra "O Bom Crioulo", de autoria

\footnotetext{
${ }^{3}$ A despeito de termos assim procedido no campo de pesquisa referente aos acórdãos de inteiro teor, há área do site dedicada especificamente à pesquisa de acórdãos integrantes da COLAC. Veja-se: http://www.stf.jus.br/portal/colac/pesquisarColac.asp (acesso em: 09 mai. 2014). De qualquer forma, nossa experiência mostra que há integração da COLAC para com a base de dados "geral" de acórdãos constantes do site do STF.

${ }^{4}$ O Tribunal de Segurança Nacional existiu entre 1936 e 1945. Para saber mais sobre este órgão (a respeito do qual não há vasta abundância de escritos), Cf. Balz, Christiano Celmer (2009). O Tribunal de Segurança Nacional: Aspectos legais e doutrinários de um tribunal da Era Vargas (1936-1945). Dissertação (Mestrado em Direito) - Centro de Pós-Graduação em Direito - CPGD, Universidade Federal de Santa Catarina, Florianópolis-SC. Disponível em: <http://www.egov.ufsc.br/portal/conteudo/o-tribunal-de-segurançanacional-aspectos-legais-e-doutrinários-de-um-tribunal-da-era-varga>. Acesso em: 09 mai. 2014.

${ }^{5}$ Veja-se que a Resolução № 230, de 2002, inclusive conforme atualizada pela Resolução № 394, de 2009, ambas do STF, trazem o RAL - Recurso de Apreensão de Livro dentre as siglas de processos extintos no âmbito daquela corte.
} 
de Adolfo Caminha ${ }^{6}$, teriam sido apreendidos pela Secretaria de Segurança Pública do Estado de São Paulo.

A alegação era a de que a obra tipificava crime previsto nos arts. $7^{\circ}$ e $8^{\circ}$ da Lei Federal ํㅜ 136, de 1935. Fazemos o resgate histórico dos dispositivos ${ }^{7}$, hoje já não mais vigentes:

Art. $7^{\circ}$ Abusar, por meio de palavras, inscripções, gravuras na imprensa, da liberdade de crítica, para, manifestamente, injuriar os poderes públicos ou os agentes que o exercem: pena de 6 meses a 2 anos de prisão.

Art. 8o Provocar ou incitar, por meio de palavras, gravuras ou inscripções de qualquer especie, o desprezo, o desrespeito ou o dia contra as forças armadas da União: Pena de 6 mezes a 2 anos de prisão cellular.

Paragrapho unico. O disposto no presente artigo applica-se ás polícias militares.

Relata-se que a obra incorreria nos dispositivos por resultar em descrédito às Forças Armadas, notadamente à Marinha, por narrar situações de severos castigos físicos ocorridos durante o serviço (dentre os quais a "chibata"). Além disso, a obra contava com personagens homossexuais e cenas de teor sexual.

A lei dispunha que, em tais situações, cabia à autoridade apreensora comunicar o fato da tomada dos livros ao juiz federal da seção. No mais, o autor, editor ou interessados teriam o direito de contestar a apreensão em juízo. Veja-se o texto direto ${ }^{8}$ da Lei Federal no 38 (a tão famigerada "Lei de Segurança Nacional"), também de 1935:

Art. 25. Quando os crimes definidos nesta lei forem praticados por meio da imprensa, proceder-se-á, sem prejuizo da acção penal competente, á apprehensão das respectivas edições. A execução desta medida competirá, no Districto Federal, ao Chefe de Policia, e nos Estados e no Territorio do Acre, á autoridade policial de maior graduação no logar,

$\S 1^{\circ} \mathrm{A}$ autoridade, que houver determinado a apprehensão, communicará o facto immediatamente ao juiz federal da secção, remettendo-Ihe um exemplar da edição apprehendida.

$\S 2^{\circ}$ Dentro de dois dias, a contar do recebimento da comunicação pelo juiz, ou antes, poderá o interessado impugnar o acto da autoridade. Ouvida esta em igual prazo decidirá o juiz, em tres dias improrogaveis, da legalidade da apprenhensão.

$\S 3^{\circ}$ (omissis)

§ 4o Da decisão caberá recurso para instancia superior, com o processo do recurso criminal.

\footnotetext{
${ }^{6}$ Faça-se menção ao fato de que, nos dias de hoje, "O Bom Crioulo" é considerado inequívoco clássico da literatura, sendo inclusive obra de leitura obrigatória em algumas provas de admissão ao ensino superior (vestibulares).

${ }^{7}$ A redação, nos padrões de hoje já ortograficamente inadequada, segue, por óbvio, o formato original da época. Nossa fonte não poderia ser outra: 0 próprio site do Planalto: http://www.planalto.gov.br/ccivil_03/leis/1930-1949/L0136impressao.htm. Acesso em: 09 mai. 2014.

${ }^{8}$ Extraído de: http://www.planalto.gov.br/ccivil_03/leis/1930-1949/L0038impressao.htm. Acesso em: 28 fev. 2014.
} 
Ocorre que o juiz federal ${ }^{9}$ vem a decidir pela ilegalidade da apreensão. Por este

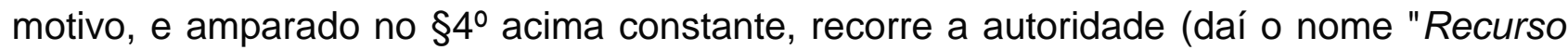
de Apreensão de Livro") ao então existente Tribunal de Segurança Nacional.

O TSN se declara incompetente para julgar o caso (entende que só poderia julgar recurso contra apreensão julgada legal e no âmbito de um processo criminal), pelo que os autos vem a ser remetidos ao STF. Este, por sua vez, considera o TSN competente, devolvendo-Ihe a incumbência do julgamento.

Os detalhes do caso, o leitor já deve ter percebido, nos são importantes para a reflexão que queremos transmitir, mas não constituem o foco de nossa análise no presente escrito. De passagem, ficam como registro histórico de considerável importância, eis que aparentemente pouco se encontra ${ }^{10}$, nas bases de pesquisa usuais, qualquer material sobre esta hoje extinta modalidade processual.

\section{O recurso de apreensão de livro e os tempos em que vivemos. A importância de olhar para trás}

É fato histórico que o contexto de expedição da decisão que acima apresentamos é extremamente turbulento. Tem-se, ainda, clara notícia de que os direitos fundamentais, mesmo os garantidos pelas Constituições da época (a de 1934, e, posteriormente, a de 1937), não tinham ampla observância pelas autoridades no período ${ }^{11}$. A Carta simboliza um tempo de nacionalismo e obsessão pela segurança ${ }^{112}$, pautado pelo temor das guerras, em que vasta gama dos direitos constitucionalmente garantidos estavam sujeitos à suspensão repentina.

Por outro ângulo, não é novidade à história que a Carta de 1934 trouxe inovações ao período: o voto feminino; a criação das Justiças do Trabalho e Eleitoral; as inúmeras

\footnotetext{
${ }^{9}$ A julgar isoladamente pelo conteúdo da decisão que consta do acórdão do STF, o entendimento do juiz federal parece-nos dotado de brilhantismo, razão pela qual nos permitimos fazê-la constar como Anexo a este breve escrito. Infelizmente, não há menção ao nome do magistrado que proferiu a decisão.

${ }^{10}$ Baseio-me nas tentativas que realizei, quando da confecção deste texto, de encontrar estudo ou escrito específico sobre a figura do Recurso de Apreensão de Livro.

${ }^{11}$ Cf. Villa, Marco Antônio (2011). A história das Constituições Brasileiras - 200 anos de luta contra o arbítrio, São Paulo: LeYa, p. 33.

${ }^{12}$ Ibidem.
} 


\section{Passagens. Revista Internacional de História Política e Cultura Jurídica}

Rio de Janeiro: vol. 7, n⿳‥1, janeiro-abril, 2015, p. 94-108.

cláusulas de proteção trabalhista, inclusive o reconhecimento aos sindicatos; dentre outras facetas que Ihe atribuíram a característica de progressista, especialmente quando comparada à Carta anterior.

Não obstante, o período é marcado pelo autoritarismo ${ }^{13}$.

O Recurso de Apreensão de Livro é por nós aqui apresentado com o objetivo de incitar a reflexão sobre os tempos em que hoje vivemos. Já tivemos a institucionalização jurídica de um meio processual onde a autoridade poderia se insurgir contra o Judiciário por este ter julgado ilegal uma apreensão de livros. Apreensão esta que, note-se, tem por base o conteúdo do texto da obra, e não qualquer outro.

Ingressamos hoje na faculdade de Direito para aprender o que já é pressuposto. Direitos como o da liberdade de expressão e livre manifestação são tidos como óbvios, incontestáveis. Não há cabimento ou seriedade em se afirmar pela inexistência destes direitos nos dias de hoje.

E, por incrível que pareça, nem então. Diz a própria Constituição de 1934 (vigente à época do início do processo, ainda que não à época do proferimento da decisão no Recurso de Apreensão de Livro):

Art 113 - A Constituição assegura a brasileiros e a estrangeiros residentes no País a inviolabilidade dos direitos concernentes à liberdade, à subsistência, à segurança individual e à propriedade, nos termos seguintes:

[...]

9) Em qualquer assunto é livre a manifestação do pensamento, sem dependência de censura, salvo quanto a espetáculos e diversões públicas, respondendo cada um pelos abusos que cometer, nos casos e pela forma que a lei determinar. Não é permitido anonimato. É segurado o direito de resposta. A publicação de livros e periódicos independe de licença do Poder Público. Não será, porém, tolerada propaganda, de guerra ou de processos violentos, para subverter a ordem política ou social.

De qualquer forma, a Constituição de 1937 também dispõe:

DOS DIREITOS E GARANTIAS INDIVIDUAIS

Art 122 - A Constituição assegura aos brasileiros e estrangeiros residentes no País o direito à liberdade, à segurança individual e à propriedade, nos termos seguintes:

$[\cdots]$

\footnotetext{
${ }^{13}$ Tal fato é notório e decorre da própria leitura da Constituição. O livro de Villa, já citado, traz um texto sobre o tema. Adicionalmente, recomendamos a leitura dos materiais de autoria do CPDOC/FGV, disponíveis em http://cpdoc.fgv.br/. Acesso em: 09 mai. 2014.
} 
15) todo cidadão tem o direito de manifestar o seu pensamento, oralmente, ou por escrito, impresso ou por imagens, mediante as condições e nos limites prescritos em lei. (Vide Decreto no 10.358, de 1942)

Certamente ninguém argumentaria haver espaço para uma figura como a do Recurso de Apreensão de Livro nos dias de hoje, porque sequer imaginamos a possibilidade de apreensão de livros sob a alegação de que o conteúdo é "subversivo". O fundamento jurídico lógico e automático seria o art. 5ำ, IV da Constituição de 1988, dentre inúmeros outros que dele decorrem (tais como o inciso IX).

Ora, vimos que, à época, as Constituições também traziam como direitos a livre manifestação do pensamento. Não obstante, era plenamente aceitável a apreensão, do ponto de vista jurídico. Veja-se, ainda, que a Constituição de 1934 (sob a égide da qual ocorreu a apreensão) sequer falava que o direito "seria exercido na forma da lei" ou expressão equivalente (como ocorre com a Carta de 1937).

O caso em tela é um exemplo concreto claríssimo da importância do que conhecemos como mutação constitucional.

O significado deste termo técnico-doutrinário não deve ser novidade ao leitor. De qualquer forma, é conveniente realizarmos breve citação a respeito:

\section{III- MUTACCÃO CONSTITUCIONAL}

$O$ estudo do poder constituinte de reforma instrui sobre o modo como o Texto Constitucional pode ser formalmente alterado. Ocorre que, por vezes, em virtude de uma evolução na situação de fato sobre a qual incide a norma, ou ainda por força de uma nova visão jurídica que passa a predominar na sociedade, a Constituição muda, sem que as suas palavras hajam sofrido modificação alguma. O texto é o mesmo, mas o sentido que lhe é atribuído é outro. Como a norma não se confunde com o texto, repara-se, aí, uma mudança da norma, mantido o texto. Quando isso ocorre no âmbito constitucional, fala-se em mutação constitucional.

A nova interpretação há, porém, de encontrar apoio no teor das palavras empregadas pelo constituinte e não deve violentar os princípios estruturantes da Lei Maior; do contrário, haverá apenas uma interpretação inconstitucional. ${ }^{14}$ (grifos nossos)

Temos textos constitucionais muito similares nas cartas de 1934, 1937 e 1988 no que concerne à garantia de liberdade de expressão. Logo, fica muito clara a importância, neste ponto, da profunda mudança no conteúdo interpretativo do princípio, a despeito da similitude na norma escrita.

\footnotetext{
${ }^{14}$ Mendes, Gilmar Ferreira; Branco, Paulo Gustavo Gonet (2013). Curso de Direito Constitucional. 7. ed., São Paulo: Saraiva. p. 169.
} 


\section{Passagens. Revista Internacional de História Política e Cultura Jurídica \\ Rio de Janeiro: vol. 7, n⿳…, janeiro-abril, 2015, p. 94-108.}

Que se coloque o leitor a refletir sobre o quanto mudou o Direito, que se propõe a estudar, nestes recentes anos. Há pouquíssimos anos, admitíamos o controle estatal direto do conteúdo de produções artísticas e literárias, com apreensão forçada das obras tidas como violadoras, como no caso. Tal era a prática dos tribunais reconhecida e fluida. Havia até sigla oficial de registro processual para protocolar autos com discussões desta natureza (Recurso de Apreensão de Livro - "RAL"). Já nos dias de hoje, a despeito das normas terem conteúdo similar, uma construção jurídica com tais conclusões soa como insanidade.

É comum nos dias de hoje, por exemplo, a judicialização de casos envolvendo aspectos da liberdade de expressão. Sabe-se que a fronteira entre o livre discurso e o abuso ao mesmo (caracterizando o delito contra a honra) é tênue, eis que casuística e totalmente subjetiva ${ }^{15}$. Temos visto com frequência notícias de livros e publicações que tiveram sua comercialização interrompida por ordem judicial ${ }^{16}$. A viabilidade de publicação de biografias não autorizadas, por exemplo, foi objeto de audiência pública realizada no âmbito do Supremo Tribunal Federal ${ }^{17}$. Ou seja, é possível ver que discussões como às mantidas quando do julgamento do Recurso de Apreensão de Livro № 1, em 1935, ainda persistem nos dias de hoje, mesmo que (por óbvio) com panos de fundo distintos.

De fato, não se tem um sistema jurídico perfeito no Brasil (e em que local se há?). O operar do Direito gera muitas dúvidas, insegurança, e não raro produz incoerências e injustiças.

Entretanto, é necessário voltar-se ao passado para avaliarmos, pelo menos quanto a um dentre inúmeros aspectos, o quanto avançamos. Tal importância assume ainda maior relevância quando nos dirigimos às gerações mais recentes de juristas, nascidas justamente no período de promulgação da vigente Constituição. Isso é, como acima mencionamos, mesmo que ainda hoje testemunhemos discussões sobre a apreensão de certas obras por ordem judicial, já mais ninguém vislumbra assim proceder tendo em vista o caráter subversivo de determinada ordem. As discussões ficam no plano dos direitos, e

\footnotetext{
${ }^{15}$ Ora, uma pessoa pode tomar para si como difamatório algo que para outra soa absolutamente normal.

${ }^{16}$ Os casos mais notórios desta natureza, acreditamos, são a apreensão e proibição de comercialização de biografias de artistas como Noel Rosa e Roberto Carlos.

${ }_{17}$ O STF realizou audiência pública sobre o tema, convocada pela Ministra Carmen Lúcia, nos dias 21 e 22 de novembro de 2013. O objetivo foi o de obter uma pluralidade de posicionamentos e informações sobre o tema para fins de julgamento da Ação Direta de Inconstitucionalidade $n^{\circ}=4815$. Cf. http://www.stf.jus.br/portal/audienciaPublica/audienciaPublica.asp?tipo=realizada. Acesso em: 28 jul. 2014.
} 


\section{Passagens. Revista Internacional de História Política e Cultura Jurídica}

Rio de Janeiro: vol. 7, n⿳‥1, janeiro-abril, 2015, p. 94-108.

a busca é pela linha divisória entre liberdade de expressão e invasão à esfera da personalidade. Ou seja, se antes a apreensão de livros era conduzida pelo Estado, como meio de controle social, tal prática nos dias de hoje seria prontamente considerada inviável por qualquer intérprete. Não são mais naturais a qualquer jurista as premissas adotadas quando do julgamento do Recurso de Apreensão de Livro, quais sejam as de que o Estado tem a prerrogativa de exercer controle pleno de conteúdo sobre quaisquer obras $^{18}$. A situação contrária, aliás, é que deve tender à obviedade: a prevalência, sempre que não impossível, da liberdade de expressão.

Ora, os novos operadores do Direito simplesmente não viveram tempos de Recurso de Apreensão de Livro. Não costuma haver contraponto, nas faculdades e até na vida profissional, ao passado da prática jurídica e social do Brasil. Surge, com naturalidade, alguma tendência de se acreditar que o direito escrito corresponderá sempre ao direito na prática. Ora, as mesmas bases jurídicas que antigamente serviam para justificar a apreensão de livros são hoje utilizadas para imediatamente afastar tais cenários. O que ocorreu, por óbvio, foi uma mudança interpretativa quanto ao peso da liberdade de expressão como direito fundamental, constitucionalmente contemplada tanto em 1935 como hoje.

Assim, deve o intérprete atentar ao conteúdo jurídico e à construção dada pelo operador à norma, muito para além de seu texto escrito, apesar deste ser o ponto de partida da interpretação.

Tal fato, apesar de constituir o mais fundamental pilar de toda a atividade jurídica, tanto das advocacias quanto da magistratura, é constantemente negligenciado pelos operadores do Direito, que tendem, até naturalmente, a sempre interpretar a norma em sua literalidade.

Apontar para o tipo de situação que tal conduta pode ignorar (e os perigos daí decorrentes - materializados na própria possibilidade de existir um "Recurso de Apreensão de Livro") é justamente o propósito de nosso artigo.

\footnotetext{
${ }^{18}$ Por óbvio que há a possibilidade de controle de determinadas obras que sejam flagrantemente abusivas, tipificando crimes, a exemplo do decidido pelo STF no caso Ellwanger (Habeas Corpus no 82.424).
} 


\section{Referências}

Balz, Christiano Celmer (2009). O Tribunal de Segurança Nacional: Aspectos legais e doutrinários de um tribunal da Era Vargas (1936-1945). Dissertação (Mestrado em Direito) - Centro de Pós-Graduação em Direito - CPGD, Universidade Federal de Santa Catarina, Florianópolis-SC. Disponível em: <http://www.egov.ufsc.br/portal/conteudo/o-tribunal-desegurança-nacional-aspectos-legais-e-doutrinários-de-um-tribunal-da-era-varga>. Acesso em: 09 mai. 2014.

Freitas, Vladmir Passos de (2009). Pouco se sabe sobre o Tribunal de Segurança Nacional. In Revista Consultor Jurídico, São Paulo. Disponível em: $<$ http://www.conjur.com.br/2009-mai-31/brasil-sabe-tribunal-seguranca-nacional>. Acesso em: 12 mai. 2014.

Mendes, Gilmar Ferreira; Branco, Paulo Gustavo Gonet (2013). Curso de Direito Constitucional. 7. ed., São Paulo: Saraiva.

Villa, Marco Antônio (2011). A história das Constituições Brasileiras - 200 anos de luta contra o arbítrio, São Paulo: LeYa. 


\begin{abstract}
ANEXO
Decisão proferida por um magistrado federal, provavelmente no ano de 1937, ou 1938 (transcrita da página 3 do acórdão que julga o RAL (Recurso de Apreensão de Livro) 1, sem adaptação de ortografia)
\end{abstract}

"Vistos:

Acompanhado do ofício de fls. 2, o dr. Secretário de Segurança Publica do Estado fez remessa a este juízo dos autos de apreensão do livro intitulado "O Bom Creoulo", de autoria de Adolpho Caminha, efetuada "por conter o volume materia infringente da Lei de Segurança Nacional".

Verifica-se dos autos de fls. 6 e 7 terem sido apreendidos 772 exemplares da obra.

Ciente da entrada dos autos em juizo, alegou o editor, em sua defesa, negativa de qualquer intenção de infringir a Lei de Segurança e afirma ter sido publicada em 1895 a primeira edição do livro, pelo editor Domingos de Magalhães, do Rio de Janeiro, tendo alcançado grande exito, o que prova com os atestados de livreiros de fls. 14 e 15.

Ouvida a autoridade apreensora, remeteu esta, com o oficio de fls. 18, as informações prestadas pelo Superintendente de Ordem Politica e Social com as quais declara estar de pleno acordo.

Tais informações (fls. 19) apontam cenas de rude imoralidade da vida de marinheiros, "deprimentes cenas de castigos físicos a bordo", a chibata, versões correlatas e relativas a oficiais, assuntos de conversas da vida de internato de homens, e conclue: "É evidente que, enquanto vigorar a lei n. 136, de 14 de dezembro de 1935, que, no caso em apreço, teve infringidos os seus arts. $7^{\circ}$ e $8^{\circ}$, é de proceder-se nos termos do art. 26, § unico da lei n. 38 de 4 de abril de 1935", isto é, apreensão e inutilização.

No inicio de suas informações, declara a autoridade ter sido a medida solicitada pelo sr. Ministro da Marinha, a exemplo do que se fez com os exemplares que estavam à venda no Rio de Janeiro. Poderia isso desaforar o processo, se não ficasse bem claro, da portaria de fls. 4, ter sido a ordem emanada do sr. Secretario da Segurança Publica. ISTO POSTO: 
Dá-me a lei "três dias improrrogáveis" para decidir da validade da apreensão. Excedi-os quase em dobro que tanto me foi necessário para apreciar a matéria, esmagado que estou pelos serviços, quase todos urgentes, a meu cargo. $O$ livro apreendido, posto que de pequeno formato (in $8^{\circ}$ ) contem 175 páginas e, não fora a reminiscencia de leitura de há quase quarenta anos, não me seria possivel, em tão curto prazo e de permeio com outras ocupações, fazer juízo de conjunto sobre a obra que não pode ser julgada pelos topicos isolados, havidos pela polícia como criminosos.

Adolpho Caminha, autor de "O Bom Creoulo", é literato cearense que floresceu no fim do seculo passado e morreu bem moço, quando ainda muito era de esperar-se do seu talento de escritor. Deixou, alem desse livro cuja segunda edição foi agora apreendida, um romance de costumes "A Normalista", um livro de critica "Cartas Literárias", uma "plaquette" "No Paiz dos Yankees", impressões de sua viagem de instrução de guardamarinha no velho "Almirante Barroso", um romance póstumo "Tentação" alem de alguns inéditos e o indefectivel livro de versos da mocidade.

Filiou-se à escola chamada "naturalista", então em furiosa voga, a ponto de serem incompreendidos e olhados com desprezo quaisquer livros de ficção que se afastassem dos moldes dos paradigmas magistrais de Flaubert e Zola, sobretudo do ultimo que levou a escola a extremos de preocupação cientifica e de minucia realista, não sem elevado senso de construção e de critica sã a vicios sociais e politicos.

José Verissimo ( $H$. da Lit. Brasileira) entendia que, da fartura de autores e livros filiados a esse movimento, no Brasil só tres nomes merecem menção: Aluizio Azevedo, Julio Ribeiro e Raul Pompeia, conceito de toda justiça em obra de síntese com o a sua mas certamente injusto, se se tiver de expor em plano mais desenvolvido a historia da literatura nacional.

Adolpho Caminha fez parte da geração que, no Ceará, deu brilho às letras, ao tempo da "Padaria Espiritual" e do "Centro Literario". Sua obra, inclusive o livro ora apreendido, revela escritor que viria a aprimorar-se (morreu aos trinta anos) não obstante os defeitos de execução e desprimores de linguagem. Oficial de marinho demissionario, era natural buscasse fixar, num trabalho literario, cenas do meio em que passara alguns anos da vida. Escritor "realista", elegeu, nesse cenario, o assunto mais escabroso, tentando fazer a psicologia de homosexuais que são os tristes heróis da sua novela, devendo notar-se que as personagens estão reproduzidas com vigor e vivem realmente. 
Era natural referir-se, pela boca das personagens, a fatos e versões da vida de bordo dos vasos de guerra. Era indispensável, e nesses quadros é, justamente, onde mais se ressalta o talento do escritor, descrevesse surras de chibata, então em uso regulamentar na Marinha de Guerra, como não era segredo para ninguem.

Está hoje a chibata abolida da Marinha de Guerra; as "deprimentes cenas de castigos fisicos a bordo" que eram regulamentares, não mais se realizam.

Que injuria pode haver para a Marinha na descrição desses terriveis castigos, em epoca que remonta ao tempo da monarquia?

Sem buscar outros exemplos, o general Dionisio Cerqueira, nas "Reminiscencias da Campanha do Paraguay", livro primoroso e sem par, no genero, na literatura nacional, narra doloroso e medonho episodio, no acompanhamento de Cuencas, onde dois soldados foram "castigados sob as armas", isto é, espancados, à prancha, até morrerem, dilacerados sob a vista do exercito inteiro... E refere-se a castigos iguais a esse, ordenado por Osorio, infligidos por ordem de Caxias e do Conde d'Eu. Necessarios, porque os pacientes haviam cometido crimes que os faziam incursos na pena de morte, eram, contudo, ilegais, conforme explica o escritor militar: "Os generais em chefe, privados de mandarem arcabuzar, porque para isso seria mister o consentimento imperial, mandavam fazer essas execuções para exemplo. Não foram, aliás, exemplos bons, porque os imitaram comandantes que excederam muitas vezes o limite regulamentar do castigo corporal."

Não mareiam tais comentários a gloria dos grandes chefes apontados nem a honra do Exercito Nacional. Porque a descrição de cenas de surras regulamentares de chibata, há mais de cincoenta anos, em marinheiros de esquadra, há de ofender e desacreditar a Marinha de Guerra?

Quanto às cruas cenas de homosexualismo, foi preocupação do escritor fazer literatura realista, observando fatos da vidad e homens que não são educandas de internato. Nem para leitura destas se destina o livro.

A crítica elevada de erros e vícios de corporações públicas é um dos meios mais eficazes de corrigí-los, ao mesmo passo que a censura literária em torno dessas criticas acaraçoa e aumenta erros e vicios. Tal livro, certamente, não teria sido publicado se dependesse do "Visto" da Santa Inquisição ou do "Imprimatur" da Igreja, mas o foi sob a 
égide da Constituição de 1934 que reproduzindo a de 1891 e a de 1824, consagra uma das mais belas e sagradas conquistas do Direito e da razão, a liberdade de pensamento.

Os arts. $7^{\circ}$ e $8^{\circ}$ da lei $n .136$ de 14 de dezembro de 1935 não visam coibir essa liberdade, mas o ataque direto e maliciosa a instituições civis e militares.

"O Bom Creoulo", como obra de arte, pode ser condenado pela crítica literária; deve ser vedado a menores; pode ser havido como fruto pêco de uma escola literária. Nunca a sua segunda edição, como a primeira, poderá ser tida como incursa nas disposições citadas da Lei de Segurança Nacional.

Acresce que o seu atual editor, publicando-o, não parece poder ser acusado de dolosamente pretender violar a lei que foi promulgada tantos anos depois da primeira edição, com objetivo certo de impedir propagandas subversivas bem definidas, e não empecer a produção de obras de pura arte. Longe iriamos, para traz, se tal interpretação se desse à lei de que houvemos mister para defesa das instituições que aos brasileiros garantem a vida com dignidade.

Assim, julgo ilegal a apreensão, devendo ser restituídos os exemplares apreendidos. P. I." 